Article

\title{
Reducing Entropy Generation in MHD Fluid Flow over Open Parallel Microchannels Embedded in a Micropatterned Permeable Surface
}

Mohammad H. Yazdi ${ }^{1, *}$, Shahrir Abdullah ${ }^{2}$, Ishak Hashim ${ }^{3}$ and Kamaruzzaman Sopian ${ }^{1}$

1 Solar Energy Research Institute (SERI), Universiti Kebangsaan Malaysia, 43600 UKM, Bangi, Selangor, Malaysia; E-Mail: ksopian@vlsi.eng.ukm.my

2 Department of Mechanical and Materials Engineering, Faculty of Engineering and Built Environment, Universiti Kebangsaan Malaysia, 43600 UKM, Bangi, Selangor, Malaysia;

E-Mail: shahrir@ukm.my

3 School of Mathematical Sciences, Faculty of Science and Technology, Universiti Kebangsaan Malaysia, 43600 UKM, Bangi, Selangor, Malaysia; E-Mail: ishak_h@ukm.my

* Author to whom correspondence should be addressed; E-Mail: mohammadhossein.yazdi@gmail.com; Tel.: +603-8921-4596; Fax: +603-8921-4593.

Received: 26 July 2013; in revised form: 7 October 2013 / Accepted: 21 October 2013 / Published: 6 November 2013

\begin{abstract}
The present study examines embedded open parallel microchannels within a micropatterned permeable surface for reducing entropy generation in MHD fluid flow in microscale systems. A local similarity solution for the transformed governing equations is obtained. The governing partial differential equations along with the boundary conditions are first cast into a dimensionless form and then the reduced ordinary differential equations are solved numerically via the Dormand-Prince pair and shooting method. The dimensionless entropy generation number is formulated by an integral of the local rate of entropy generation along the width of the surface based on an equal number of microchannels and no-slip gaps interspersed between those microchannels. Finally, the entropy generation numbers, as well as the Bejan number, are investigated. It is seen that surface-embedded microchannels can successfully reduce entropy generation in the presence of an applied magnetic field.
\end{abstract}

Keywords: MHD; similarity solution; permeable surface; open parallel microchannels; entropy production 


\section{Nomenclature}

$A \quad$ a constant at prescribed surface temperature

$B \quad$ magnetic induction $\left[\mathrm{Wb} \mathrm{m}^{-2}\right.$ ]

$B e \quad$ Bejan number

$\mathrm{Br} \quad$ Brinkman number

$C_{f} \quad$ local skin-friction coefficient

$c_{p} \quad$ specific heat at constant pressure $\left[\mathrm{J} \mathrm{kg}^{-1} \mathrm{~K}^{-1}\right]$

$d \quad$ depth of microchannel [m]

Ec Eckert number

$f \quad$ dimensionless function

$f_{w} \quad$ suction/injection parameter

$K \quad$ slip coefficient

$k_{\infty} \quad$ thermal conductivity [ $\mathrm{W} \mathrm{m}^{-1} \mathrm{~K}^{-1}$ ]

$k^{\prime} \quad$ surface temperature parameter

$L \quad$ characteristic length scale [m]

$l \quad$ slip length [m]

$M \quad$ magnetic parameter

$m^{\prime} \quad$ number of microchannels

$N u_{x} \quad$ local Nusselt number

$\mathrm{P} \quad$ Pressure $[\mathrm{Pa}]$

Pr Prandtl number

$\mathrm{Re}_{\mathrm{x}} \quad$ local Reynolds number

$S_{F}^{\prime \prime \prime} \quad$ friction irreversibilities $\left[\mathrm{W} \mathrm{m} \mathrm{m}^{-3} \mathrm{~K}^{-1}\right.$ ]

$S_{g}{ }^{\prime \prime \prime} \quad$ local volumetric rate of entropy generation [ $\mathrm{W} \mathrm{m}^{-3} \mathrm{~K}^{-1}$ ]

$S_{g}{ }^{\prime \prime} \quad$ local rate of entropy generation based on integration over width of the surface $\left[\mathrm{W} \mathrm{m}^{-2} \mathrm{~K}^{-1}\right.$ ]

$S_{g 0}{ }^{\prime \prime} \quad$ characteristic entropy generation rate $\left[\mathrm{W} \mathrm{m}^{-2} \mathrm{~K}^{-1}\right]$

$S_{M}^{\prime \prime \prime} \quad$ magnetic irreversibilities [ $\left[\mathrm{W} \mathrm{m}^{-3} \mathrm{~K}^{-1}\right.$ ]

$S_{T}^{\prime \prime \prime} \quad$ heat transfer irreversibilities $\left[\mathrm{W} \mathrm{m}^{-3} \mathrm{~K}^{-1}\right]$

$T_{w} \quad$ temperature at the surface [K]

$T \quad$ temperature of the fluid within the boundary layer $[\mathrm{K}]$

$T_{\infty} \quad$ temperature of the ambient fluid [K]

$u_{\infty} \quad$ free stream velocity $\left[\mathrm{m} \mathrm{s}^{-1}\right]$

$u, v \quad$ the $x$-, $y$-components of velocity $\left[\mathrm{m} \mathrm{s}^{-1}\right]$

$W \quad$ width of plate [m]

Ws $\quad$ width of microchannel [m]

$X \quad$ non-dimensional surface length, $x L^{-1}$

$x, y \quad$ distance along and normal to the surface [m]

$z \quad$ coordinate along width of the surface

Greek

$\alpha \quad$ thermal diffusivity $\left[\mathrm{m}^{2} \mathrm{~s}^{-1}\right]$ 


$\begin{array}{ll}\zeta & \text { surface parameter, } d W^{-1} \\ \eta & \text { similarity variable } \\ \theta & \text { dimensionless temperature } \\ \lambda & \text { surface parameter, }(W s+2 d) W^{-1} \\ \mu_{\infty} & \text { dynamic viscosity }[\mathrm{Pa} \mathrm{s}] \\ v_{\infty} & \text { kinematic viscosity }\left[\mathrm{m}^{2} \mathrm{~s}^{-1}\right] \\ \rho & \text { fluid density }\left[\mathrm{kg} \mathrm{m}^{-3}\right] \\ \sigma & \text { electrical conductivity of the fluid }\left[\mathrm{S} \mathrm{m}^{-1}\right] \\ \Phi & \text { irreversibility distribution ratio } \\ \Omega & \text { dimensionless temperature difference }\end{array}$

Subscripts

$\begin{array}{ll}n s & \text { no-slip condition } \\ s & \text { slip condition } \\ w & \text { surface condition } \\ \infty & \text { ambient condition }\end{array}$

\section{Introduction}

Magnetohydrodynamics (MHD) has potential in many engineering branches, predominantly in the field of microfluidics, such as MHD micropumps [1,2], biological transportation, and drug delivery [3,4]. A precise microfluidic application of the problem is micromixing technology which is vital in biological processes, especially in rapid mixing of a biological fluid in a microchannel [5]. Lorentz forces produced by an applied magnetic field in a moving electrically conducting fluid are able to push fluids in the mixing process without a need for any mechanical components with the device. Suction can be utilized to biological chemical processes to remove reactants while blowing is applied to add reactants in the process and to cool the surface body by its ability of decreasing heat transfer rate. Thus, surface permeability (suction/injection) is an effect that has practical applications in boundary layer control of microscale systems. Accordingly, the MHD field is of interest in connection with certain problems of the movement of physiological electrically conducting fluids in the open or closed microchannels with the need for theoretical research on the problem of MHD boundary layer flow along permeable surfaces.

Recently, the use of open microchannels instead of the usual closed microchannels has been recommended, since the open microchannels are open to the ambient air on the top side, which can offer advantages, such as maintaining the physiological conditions for normal cell growth and introducing accurate amounts of chemical and biological materials [6,7]. Taking advantages of microfabrication techniques due to making appropriate slip boundary condition along hydrophobic open microchannels together with biotechnological application areas of open microchannels motivates us to consider carefully a practical design for controlling the entropy production of various microscale systems in a MHD flow field. As a shape optimization technique, entropy generation analysis based on surface microprofiling (EBSM) considers optimal microprofiling of a micropatterned surface to minimize entropy production. This technique can reduce the frictional pressure drop, while transferring a specified heat flow from the surface wall to the fluid. Dissimilar past techniques of modelling surface 
roughness by an effective friction factor, the new method of EBSM develops analytical solutions for the embedded open microchannels (microgrooves) to give more carefully optimized surface characteristics [8]. The analysis of the flow field in a boundary layer adjacent to the wall is very important in the present problem, and is an essential part in the area of fluid dynamics and heat transfer. Particularly, understanding boundary layer flows and heat transfer of MHD fluid flows has become important recently. Since we are interested to investigate an open microchannel system with the partial slip, we would consider carefully, the slip boundary layer flow and heat transfer over the surface in various situations.

A literature survey indicates that there is an extensive literature available regarding the boundary layer flow over surfaces in various situations. Such studies include different fluid models, MHD and hydrodynamic cases, with and without slip boundary conditions. Regarding external slip flow regimes based on horizontal surfaces, Martin and Boyd analysed the Blasius boundary layer problem in the presence of slip boundary conditions [9]. They applied a similarity transformation technique as an exact solution to obtain ordinary differential equations of the problem and also they defined a non-dimensional parameter for introducing hydrodynamic slip along the external boundary layer flow, called slip coefficient $(K)$, which is related to both fluid characteristic flow and the slip length. Their results demonstrated that the boundary layer equations can be used to study flow at MEMS scale and provide useful information to study the effects of rarefaction on the shear stress and structure of the flow. In another work [10], they have analysed slip flow and heat transfer at constant wall temperature. According to their studies of liquid slip flow over flat plate at constant wall temperature boundary conditions, there is no temperature jump in liquids. The same problem has been studied by Vedantam [11] with three different models for the slip flow. Later, Yazdi et al. [12] investigated the slip boundary layer flow past flat surface under constant heat flux boundary conditions. They investigated the velocity slip effects on both gas and liquid flows. They also illustrated that hydrodynamic slip can increase heat transfer rate in liquid flow case. In a later work, they [13] considered the effect of permeability parameters on the slip flow regime. The findings of this study indicate that mass suction has a significant effect on the fluid velocity adjacent to the wall in the presence of partial slip. Later, a laminar mixed convection over an isothermal vertical plate has been investigated with first-order momentum and thermal discontinuities at the wall by Cao and Baker [14]. They proved again that the slip coefficient can increase heat transfer rate in external liquid-flow problems. They indicated that wall shear stress can be decreased by more than $85 \%$ in gas flow $(\operatorname{Pr}=0.72)$ and $75 \%$ in liquid $(\operatorname{Pr}=7.0)$ as the slip coefficient varies from 0 to 5 . In addition, the decrease in wall shear stress is found to be more substantial in stronger buoyancy flows. Furthermore, a boundary layer slip flow over a flat plate under constant heat flux condition at the surface is studied by Aziz [15]. Later, the study of slip MHD flow and heat transfer over an accelerating continuous moving surface is evaluated by Yazdi et al. [16,17]. They have investigated MHD liquid flow over permeable continuous moving surfaces in the presence of the partial slip and high-order chemical reactions. The effect of thermal slip conditions over a permeable stretching sheet was taken into account in the work by Hayat et al. [18], whilst, more recently, Qasim et al. [19] added the effects of thermal radiation and ohmic dissipation. Besides, the heat and mass transfer characteristics of MHD viscous flow over a permeable continuous surface under both hydrodynamic and thermal slip conditions is solved analytically by Turkyilmazoglu [20]. Moreover, MHD boundary layer flow over a flat plate with slip boundary condition is investigated 
by Bhattacharyya [21]. A local non-similarity transformation has evaluated the flow and heat transfer over a flat plate with partial slip subjected to the convective surface heat flux at the boundary by Rahman [22]. After that, Yazdi et al. [23] have evaluated the effects of viscous dissipation on the slip MHD flow and heat transfer past a permeable surface with convective boundary conditions. They illustrated moving magnetic lines of force increases the fluid motion in the boundary layer flow since the free stream velocity, $u_{\infty}$, outside the boundary layer is also affected by magnetic field, so it can push the boundary layer forward since the value of the free stream velocity is higher compared to the velocity inside the boundary layer region. In the above literatures, it is found that a significant drag reduction could be achieved because of the partial slip along the various surface situations. Evaluation of this drag reduction in various microfluidic application areas is significant due to the reduction of exergy losses.

The EBSM was developed for the first time by Naterer [24,25] who projected surface microprofiling to reduce energy dissipation in convective heat transfer. This technique includes local slip-flow conditions within the embedded open microchannels and thus tends to drag reduction and lower exergy losses along the surface [25]. He noted that fully no-slip conditions are expected outside of the microchannels while a slip boundary condition exists in open microchannels [24]. In a comprehensive study, Naterer [26] concentrated specifically on open parallel microchannel surface design. He attempted to optimize the microscale features of the surface. The optimized number of channels, spacing between microchannels and aspect ratios were modelled to give an effective compromise between friction and heat transfer irreversibilities. His results suggested that embedded surface microchannels can successfully reduce entropy generation in external forced convection problems of viscous flow over a flat surface [26]. In a subsequent novel work, Naterer et al. [27] have applied this method both experimentally and numerically to the special application of aircraft intake de-icing. Later, a study based on liquid flow is investigated by Yazdi et al. [28]. In another study, they [29] have analysed the second law analysis of MHD flow over embedded microchannels in an impermeable surface. Recently, Yazdi et al. [7] have investigated entropy generation analysis of electrically conducting fluid flow over open parallel microchannels embedded within a continuous moving surface in the presence of applied magnetic field where the free stream velocity was stationary and the fluid was moving by an external surface force.

In the present study, the free stream velocity plays an important role in fluid transportation which has not been considered in the previous studies. Thus, the Lorenz force can push the fluid forward to accelerate the fluid motion. The EBSM can also be recommended here as an appropriate technique due to evaluation of MHD flow in microscale systems in the presence of partial slip. Such innovations can examine entropy production of existing microscale systems by embedding microdevices into surfaces. There have been numerous analytical or numerical researches developed particularly for entropy generation analysis of boundary layer flow. Though, to the best of our knowledge, no research has have been done yet to not only analyze the local entropy generation of MHD fluid flow over embedded permeable surface microchannels, but also to reach to a liquid transportation design in micro scale MHD systems with the reduction in the entropy production. Therefore, the objectives of this research study are as follows: 
- To analyse entropy generation of an electrically conducting fluid flow over open parallel microchannels embedded within stationary permeable surface in the presence of a transverse magnetic field at PST.

- To evaluate the effects of the slip coefficient, magnetic parameter, permeability (suction/injection), surface temperature parameter as well as, number of open microchannels, group parameter and microchannels geometric parameters, on both entropy generation number and Bejan number.

- Finally, to evaluate the reduction of entropy generation by embedded open parallel microchannels within the permeable surface in order to reach a liquid transportation design in microscale MHD systems.

\section{Flow and Heat Transfer Analysis}

First, we prepare the flow and heat transfer mathematical formulation of the 2D steady MHD flow past a permeable stationary surface in the presence of partial slip at prescribed surface temperature (PST). The flow configuration is illustrated in Figure 1a. After that, the utilisation of the second law of thermodynamics is focused on EBSM which requires simultaneous modelling of the slip and no-slip boundary condition along the width of the micropatterned surface (see Figure 1b). It is assumed that the width of the surface consists of a specific number of open microchannels and the base sections $(\mathrm{m})$, each of which has its own width. Moreover, a no-slip condition is applied between open microchannels, whereas a slip condition is applied to the open parallel microchannels. Thus, in the present micropatterned surface design, based on EBSM techniques of gas or liquid flow [7,8,25,27], the slip boundary condition is applied inside the open microchannels. Experimental evidence recommends that, for water flowing through a microchannel, the surface of which is coated with a $2.3 \mathrm{~nm}$ thick monolayer of hydrophobic octadecyltrichlorosilane, an apparent hydrodynamic slip is measured just above the solid surface. This velocity is about $10 \%$ of the free-stream velocity [30]. It is assumed that the electrically conducting fluid is incompressible, Newtonian and continuum with free stream velocity $u_{\infty}$ and temperature $T_{\infty}$. Furthermore, the magnetic Reynolds number is assumed small and the induced magnetic field is neglected. Here, a transverse magnetic field is applied in the vertical direction with varying strength $B$, as a function of $x$, is given by:

$$
B(x)=B_{0} x^{-\frac{1}{2}}, \quad B_{0} \neq 0
$$

where $x$ is the coordinate along the plate measured from the leading edge. A permeable surface is considered with mass transfer velocity as a function of $x$ :

$$
v_{w}(x)=v_{w 0} x^{-\frac{1}{2}}, \quad v_{w 0} \neq 0
$$

The positive $y$-coordinate is measured perpendicular to the $x$-coordinate in the outward direction towards the fluid. The corresponding velocity components in the $x$ and $y$ directions are denoted as $u$ and $v$, respectively (see Figure 1). The surface is at prescribed surface temperature (PST), $T_{\text {wall }}$ given as:

$$
y=0, \quad T=T_{\text {wall }}\left(=T_{\infty}+A x^{k^{\prime}}\right)
$$


where $A$ is a constant and $k^{\prime}$ is the surface temperature parameter at the prescribed surface temperature (PST) boundary condition.

Figure 1. (a) Physical model of fluid flow and heat transfer in the present work; (b) open parallel microchannels embedded within permeable surface. (The subscripts of $n s$ and $s$ refer to no-slip and slip conditions, respectively.)

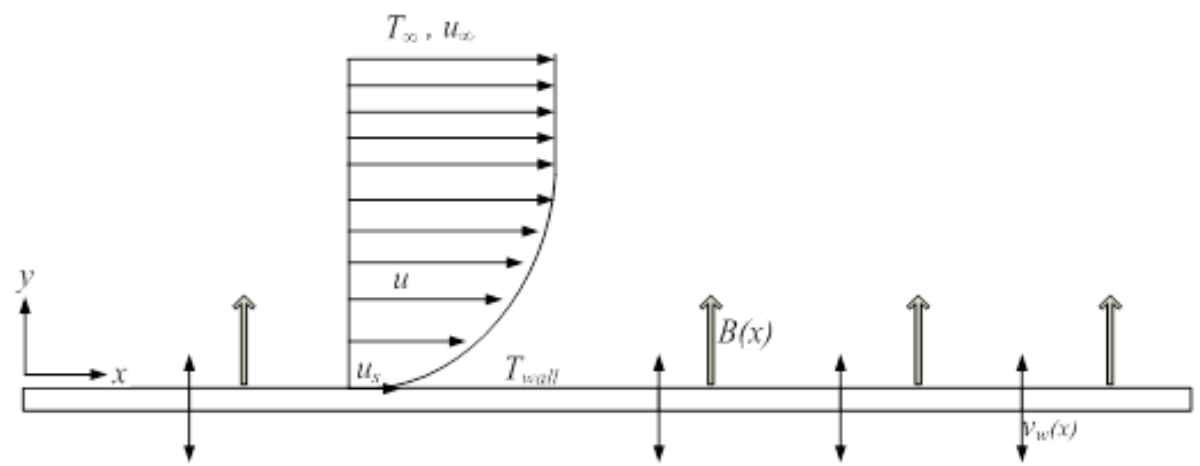

(a)

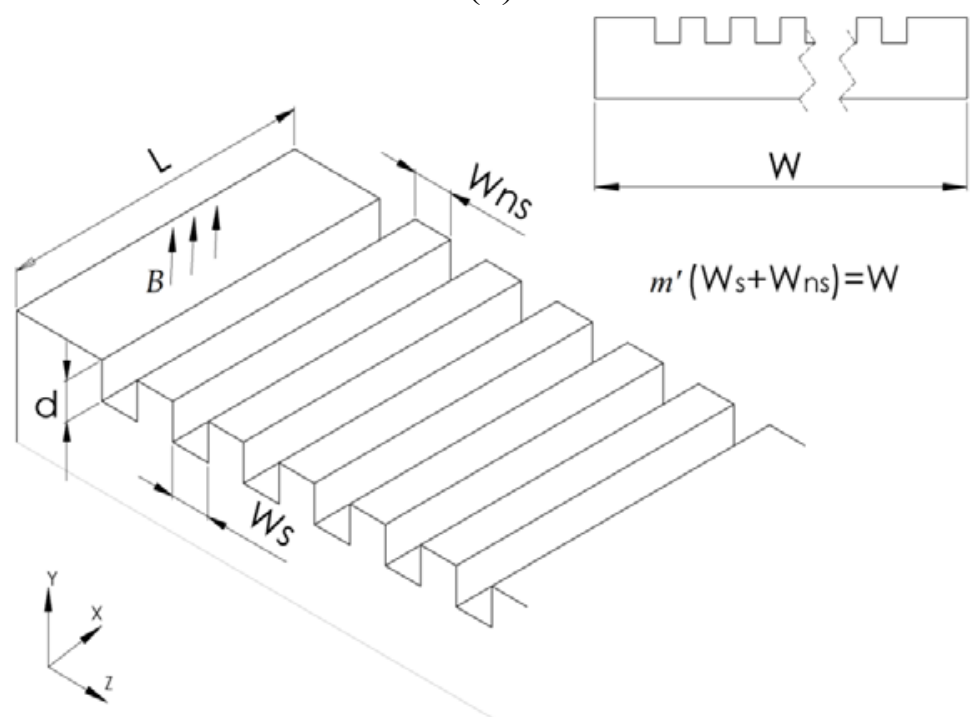

(b)

The boundary layer equations governing the MHD convective heat transfer in the presence of viscous dissipation are written in the usual notation as:

$$
\begin{gathered}
\frac{\partial u}{\partial x}+\frac{\partial v}{\partial y}=0 \\
u \frac{\partial u}{\partial x}+v \frac{\partial u}{\partial y}=v_{\infty} \frac{\partial^{2} u}{\partial y^{2}}-\frac{\sigma B^{2}}{\rho} u+\frac{\sigma B^{2}}{\rho} u_{\infty} \\
u \frac{\partial T}{\partial x}+v \frac{\partial T}{\partial y}=\alpha \frac{\partial^{2} T}{\partial y^{2}}+\frac{v_{\infty}}{c_{p}}\left(\frac{\partial u}{\partial y}\right)^{2}
\end{gathered}
$$

where $v_{\infty}$ is the kinematic viscosity, $c_{p}$ is specific heat at constant pressure and $\alpha$ is the thermal diffusivity. The associated boundary conditions are given as: 


$$
\begin{gathered}
y=0 \Rightarrow u=u_{s}=\left.l \frac{\partial u}{\partial y}\right|_{w}, v=v_{w} \quad, T=T_{w}\left(=T_{\infty}+A x^{k^{\prime}}\right) \\
y \rightarrow \infty \Rightarrow u=u_{\infty}, T=T_{\infty}
\end{gathered}
$$

where $u_{s}$ is the hydrodynamic slip, assumed to be proportional to the local wall shear stress and $l$ is slip length, which is for Newtonian fluids typically expressed as a direct proportionality between the hydrodynamic slip and the shear rate at the wall [31-33]. The last term in the above momentum Equation (5) describes the pressure gradient, $\partial P / \partial x=\sigma B^{2} u_{\infty}$ which is obtained from the momentum equation at the edge of the boundary layer [23,34]. It is noted that the magnetic field affects the free stream velocity at the edge of the boundary layer as well. Thus, the Lorenz force at the edge of the boundary layer is much higher compared with the Lorenz force inside the boundary layer leading to push the boundary layer forward for fluid transportation aims. Besides, $v_{w}(x)$ is the mass transfer due to suction $v_{w}(x)<0$ or injection $v_{w}(x)>0$. The following non-dimensional variables are used:

$$
f^{\prime}(\eta)=\frac{u}{u_{\infty}}, \quad \eta=y \sqrt{\frac{u_{\infty}}{v_{\infty} x}}, \quad v=\frac{1}{2} \sqrt{\frac{u_{\infty} v_{\infty}}{x}}\left(\eta f^{\prime}-f\right), \quad \theta(\eta)=\frac{T-T_{\infty}}{T_{w}-T_{\infty}}
$$

The slip coefficient, $K$, using similarity variables is given by:

$$
\begin{gathered}
f^{\prime}(0)=K f^{\prime \prime}(0) \\
K=l \sqrt{\frac{u_{\infty}}{x v_{\infty}}}
\end{gathered}
$$

The fundamental partial differential Equations (5) and (6) can be transformed to ordinary differential equations by substituting similarity variables Equation (8) into Equations (5) and (6) as follows:

$$
\begin{gathered}
f^{\prime \prime \prime}+\frac{1}{2} f f^{\prime \prime}-M^{2} f^{\prime}+M^{2}=0 \\
\theta^{\prime \prime}+\frac{\operatorname{Pr}}{2} \theta^{\prime} f-\operatorname{Pr} k^{\prime} f^{\prime} \theta+\operatorname{Ec} \operatorname{Pr} x^{-k^{\prime}}\left(f^{\prime \prime}\right)^{2}=0
\end{gathered}
$$

For these momentum and energy equations, the associated boundary conditions are given as:

$$
\eta=0 \Rightarrow\left\{\begin{array}{l}
f^{\prime}(0)=K f^{\prime \prime}(0) \\
f(0)=f_{w} \\
\theta(0)=1
\end{array}, \eta \rightarrow \infty \Rightarrow\left\{\begin{array}{l}
f^{\prime}(\infty)=1 \\
\theta(\infty)=0
\end{array}\right.\right.
$$

where $f_{w}, \operatorname{Pr}$ Ec, and $M$ represent the suction/injection parameter, the Prandtl number, the Eckert number and the magnetic parameter, respectively:

$$
f_{w}=\frac{-v_{w 0}}{\frac{1}{2} \sqrt{u_{\infty} v_{\infty}}}, \quad M^{2}=\frac{\sigma B_{0}{ }^{2}}{\rho u_{\infty}}, \quad \mathrm{Ec}=\frac{u_{\infty}{ }^{2}}{A c_{p}}, \quad, \quad \operatorname{Pr}=\frac{v_{\infty}}{\alpha}
$$

It is noted that $f_{w}$ is negative for mass injection $\left(v_{w 0}>0\right)$ cases and positive in the presence of suction $\left(v_{w 0}<0\right)$ at the surface. From the definitions in Equation (14), it is obvious that $f_{w}$ and $M$ are independent of $x$. Thus, as the only parameter that exhibits a dependence on the $x$-coordinate is slip 
coefficient $K$, the problem must be solved locally. Consequently, given the fixed values of the $x$-coordinate the local similarity solution would be achieved correctly for momentum and energy equations. The nonlinear differential Equations (11) and (12) are solved numerically by applying the explicit Runge-Kutta $(4,5)$ formula, the Dormand Prince pair and the shooting method, subject to the associated boundary conditions in Equation (13). The skin friction coefficient and the local Nusselt number can be obtained as follows:

$$
\begin{gathered}
C_{f}=\frac{\tau_{w}}{\frac{1}{2} \rho u_{\infty}{ }^{2}}=\frac{\left.\mu_{\infty} \frac{\partial u}{\partial y}\right|_{y=0}}{\frac{1}{2} \rho u_{\infty}{ }^{2}}=2 \operatorname{Re}_{x}{ }^{-\frac{1}{2}} f^{\prime \prime}(0) \\
N u_{x}=\frac{-\left.x \frac{\partial T}{\partial y}\right|_{y=0}}{T_{w}-T_{\infty}}=\left|\theta^{\prime}(0)\right| \sqrt{\left(\frac{u_{\infty}}{v_{\infty}}\right)} x^{\frac{1}{2}}
\end{gathered}
$$

where $\mu_{\infty}$ is dynamic viscosity of the fluid.

\section{Entropy Generation Analysis}

Entropy generation analysis concerned with the MHD flow over open parallel microchannels embedded within a horizontal stationary permeable surface at a prescribed surface temperature (PST) is considered. Thus, heat transfer $\left(S_{T}^{\prime \prime}\right)$, friction $\left(S_{F}^{\prime \prime}\right)$, and magnetic irreversibilities $\left(S_{M}{ }^{\prime \prime}\right)$ are included within the local volumetric rate of entropy generation. The rate of entropy generation will be obtained based on the previous solutions of the boundary layer for fluid velocity and temperature. According to Woods [35] and Yazdi [7], the local volumetric rate of entropy generation in the presence of a magnetic field is given by:

$$
\begin{aligned}
& S_{g}^{\prime \prime \prime}=\frac{k_{\infty}}{T_{\infty}^{2}}\left[\left(\frac{\partial T}{\partial x}\right)^{2}+\left(\frac{\partial T}{\partial y}\right)^{2}\right]+\frac{\mu_{\infty}}{T_{\infty}}\left(\frac{\partial u}{\partial y}\right)^{2}+\frac{\sigma B^{2}}{T_{\infty}} u^{2} \\
& =S_{T}^{\prime \prime \prime}+S_{F}^{\prime \prime \prime}+S_{M}^{\prime \prime \prime}
\end{aligned}
$$

where $k_{\infty}$ is thermal conductivity. In the present work, the integration of the above local entropy generation is done only along the width of the surface (z-direction) due to considering the impact of embedded microchannels within the permeable surface. This type of integration leads to study the effects of combined slip/no-slip conditions on local entropy generation rates. With the intention of considering the effect of the embedded open parallel microchannels within a permeable surface, integration over the width of the surface is applied over the local rate of entropy generation adjacent to the wall. The cross-stream $(z)$ dependence arises from interspersed no-slip (subscript $n s$ ) and slip-flow (subscript $s$ ) solutions of the boundary layer equations. Therefore, the integration over the width of the surface from $0 \leq z \leq W$ consists of $m^{\prime}$ separate integrations over each microchannel surface width, $0 \leq z \leq W_{s}+2 d$, as well as the remaining no-slip portion of the plate, which is interspersed between these microchannels and covers a range of $0 \leq z \leq W-m^{\prime} W_{s}$ (see Figure 1b). Thus, by performing the 
integrations, and assuming an equal number of microchannels and no-slip gaps interspersed between those microchannels (see Figure 1b), it can be shown that:

$$
S_{g}^{\prime \prime}=S_{T}^{\prime \prime}+S_{F}^{\prime \prime}+S_{M}^{\prime \prime}
$$

where:

$$
\begin{aligned}
& S_{T}^{\prime \prime}=\int_{0}^{m^{\prime}\left(W_{s}+2 d\right)} S_{T, s l i p}^{\prime \prime \prime} d z+\int_{0}^{W-m^{\prime} W_{s}} S_{T, n o-s l i p}^{\prime \prime \prime} d z \\
& S_{F}^{\prime \prime}=\int_{0}^{m^{\prime}\left(W_{s}+2 d\right)} S_{F, s l i p}^{\prime \prime \prime} d z+\int_{0}^{W-m^{\prime} W_{s}} S_{F, n o-s l i p}^{\prime \prime \prime} d z \\
& S_{M}^{\prime \prime}=\int_{0}^{m^{\prime}\left(W_{s}+2 d\right)} S_{M, s l i p}^{\prime \prime \prime} d z+\int_{0}^{W-m^{\prime} W_{s}} S_{M, n o-s l i p}^{\prime \prime \prime \prime} d z
\end{aligned}
$$

As a result, the present local rate of entropy generation $S_{g}$ " is defined per meter squared above based on the integration over width of the surface. Moreover, the dimensionless local entropy generation rate is defined as a ratio of the present local entropy generation rate $S_{g}$ " and a characteristic entropy generation rate $S_{g 0}{ }^{\prime \prime}$ called entropy generation number $N_{s}$.

\subsection{Entropy Generation Number}

Here, the characteristic entropy generation rate, based on the width of the surface, is defined as:

$$
S_{g_{0}}^{\prime \prime}=\frac{k_{\infty} \Delta T^{2} W}{L^{2} T_{\infty}^{2}}
$$

where $L$ is characteristic length scale. In addition, the non-dimensional geometric parameters are defined as (see Figure 1b):

$$
\lambda=\frac{W_{s}+2 d}{W}, \quad \varsigma=\frac{d}{W}
$$

Consequently, the entropy generation number is expressed as:

$$
\begin{aligned}
& N_{s}=\frac{S_{g}^{\prime \prime}}{S_{g_{0}}^{\prime \prime}}= \\
& =\left\{\begin{array}{l}
\frac{k^{\prime 2}}{X^{2}} \theta_{s}^{2}(0)\left[m^{\prime} \lambda\right]+\frac{k^{\prime 2}}{X^{2}} \theta_{n s}^{2}(0)\left[1+2 m^{\prime} \varsigma-m^{\prime} \lambda\right] \\
+\frac{\operatorname{Re}}{X} \theta_{s}^{\prime 2}(0)\left[m^{\prime} \lambda\right]+\frac{\operatorname{Re}}{X} \theta_{n s}^{\prime 2}(0)\left[1+2 m^{\prime} \varsigma-m^{\prime} \lambda\right] \\
+\frac{B r}{\Omega} \frac{\operatorname{Re}}{X} f_{s}^{\prime \prime 2}(0)\left[m^{\prime} \lambda\right]+\frac{B r}{\Omega} \frac{\operatorname{Re}}{X} f_{n s}^{\prime \prime 2}(0)\left[1+2 m^{\prime} \varsigma-m^{\prime} \lambda\right] \\
+\frac{B r}{\Omega} \frac{M^{2} \operatorname{Re}}{X} f_{s}^{\prime 2}(0)\left[m^{\prime} \lambda\right]+\frac{B r}{\Omega} \frac{M^{2} \operatorname{Re}}{X} f_{n s}^{\prime 2}(0)\left[1+2 m^{\prime} \varsigma-m^{\prime} \lambda\right]
\end{array}\right.
\end{aligned}
$$


where $X, \operatorname{Re}, B r$ and $\Omega$ are, respectively, the non-dimensional surface length, the Reynolds number, the Brinkman number and the dimensionless temperature difference. These parameters are given by the following relationships:

$$
\begin{gathered}
B r=\frac{\mu_{\infty}\left(u_{\infty}\right)^{2}}{k_{\infty} \Delta T}, \quad \operatorname{Re}=\frac{u_{\infty} L}{v_{\infty}} \\
X=\frac{x}{L}, \quad \Omega=\frac{\Delta T}{T_{\infty}}
\end{gathered}
$$

\subsection{Bejan Number}

The Bejan number is defined as the ratio of heat transfer irreversibility to total irreversibility due to heat transfer, fluid friction and magnetic field for the laminar MHD boundary layer flow. Bejan number is given by [7]:

$$
B e=\frac{\text { Heat trans fer irreversibility }}{\text { Entropy generation number }}=\frac{1}{1+\Phi}
$$

where $\Phi$ is the irreversibility distribution ratio which is given by:

$$
\Phi=\frac{\text { Fluid friction irreversib ility }+ \text { Magnetic field irreversib ility }}{\text { Heat trans fer irreversib ility }}
$$

As the Bejan number ranges from 0 to 1, it approaches zero when the entropy generation due to the combined effects of fluid friction and magnetic field is dominant. Similarly, $B e>0.5$ indicates that the irreversibility due to heat transfer dominates, with $B e=1$ as the limit at which the irreversibility is solely due to heat transfer. Consequently, $0 \leq \Phi \leq 1$ indicates that the irreversibility is primarily due to the heat transfer irreversibility, whereas for $\Phi>1$ it is due to the sum of the fluid friction and magnetic field irreversibility. The entropy generation number, $N_{s}$ in Equation (24) together with Bejan number in Equation (26) will be used for the evaluation of the present study.

\section{Results and Discussion}

The ordinary differential Equations (11) and (12) are solved numerically subjected to the boundary conditions in Equation (13) using the Dormand-Prince pair and shooting method. Table 1 shows a comparison between the results of the present work and that of the previous work, obviously indicating a perfect agreement.

Table 1. Comparison of the wall temperature gradient between the present results and Ibrahim [36] for special case $M=0, E c=0, K=0$.

\begin{tabular}{cccc}
\hline $\operatorname{Pr}$ & $\boldsymbol{k}^{\prime}$ & Ibrahim and Hassanien [36] & Present Results \\
\hline 7 & 0 & 0.6459 & 0.6459 \\
& -0.4 & 0.2343 & 0.2343 \\
& $1 / 3$ & 0.8191 & 0.8191 \\
& 1 & 1.0435 & 1.0435 \\
\hline
\end{tabular}




\subsection{Effects on Velocity Field and Friction}

Figure 2a,b show the velocity profiles $f^{\prime}(\eta)$ and velocity gradient $f^{\prime \prime}(\eta)$, respectively, for various values of the suction/injection parameter $f_{w}$ when $K=0.5$ and $M=0.5$ which is well-matched with our previous slip MHD flow problem [23]. It is noted that, in the slip flow regime, velocity adjacent to the wall can be manipulated through suction/injection parameter. Figure $3 a, b$ illustrate the variation of the velocity $f^{\prime}(\eta)$ and velocity gradient $f^{\prime \prime}(\eta)$ profiles, respectively, for various values of slip coefficient $K$ when $f_{w}=0.2$ and $M=0.5$ [23]. An excellent agreement is also reached with the results of Figure 3, compared with Yazdi et al. [23]. It is noted that an increase in $K$ corresponds to a rise in the fluid velocity adjacent to the wall. Consequently, the wall velocity gradient decreases.

Figure 2. Distribution of velocity (a) and velocity gradient (b) as a function of $\eta$ for various values of $f_{w}$ when $K=0.5, M=0.5$.

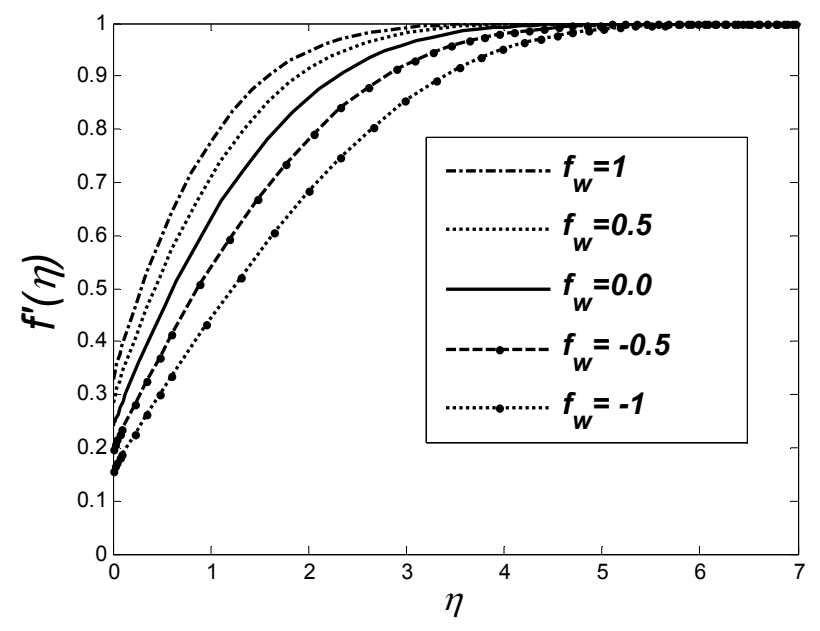

(a)

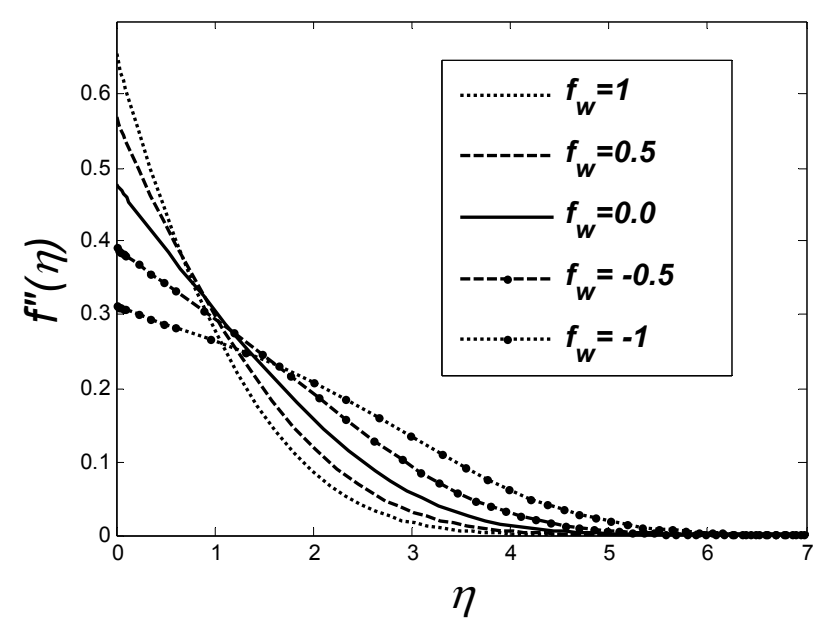

(b)

Figure 3. Distribution velocity (a) and velocity gradient (b) as a function of $\eta$ for various values of $K$ when $M=0.5, f_{w}=0.2$.

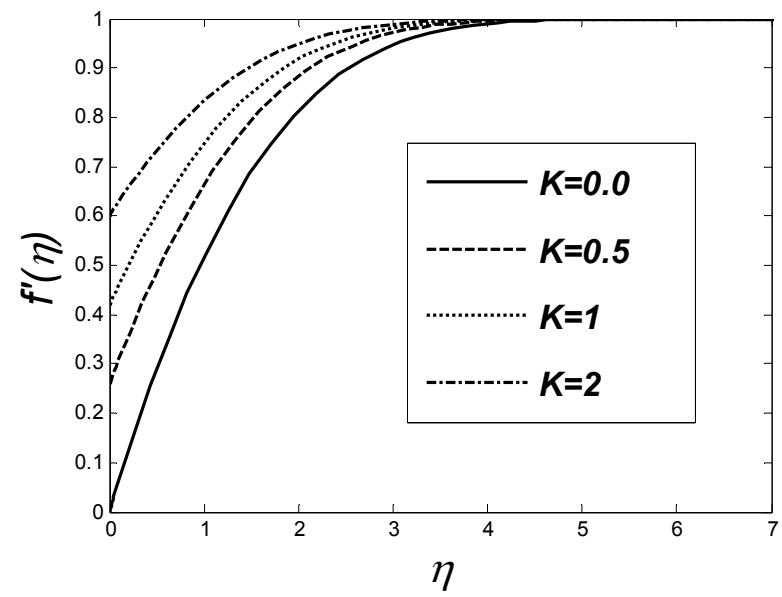

(a)

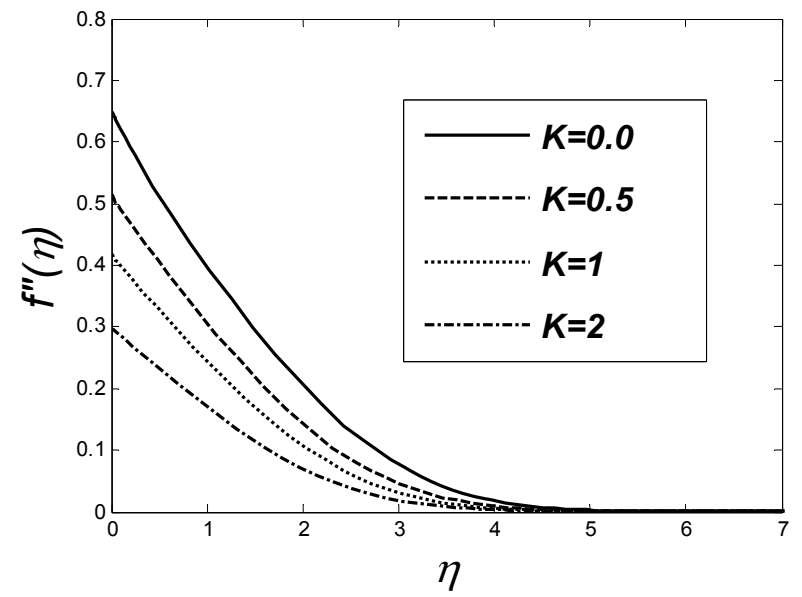

(b)

The effect of the magnetic parameter on the velocity profiles when $f_{w}=0.0, K=0.5$ has been illustrated in Figure 4a. In the presence of the slip, the magnetic parameter can effectively increase the 
fluid velocity both inside the boundary layer and adjacent to the wall. This is the reason why the magnetic field has the potential to move forward an electrically conducting fluid in the microscale system.

Figure 4. (a) Velocity distribution and (b) velocity gradient as function of $\eta$ for various values of $M$ when $f_{w}=0.0, K=0.5$.

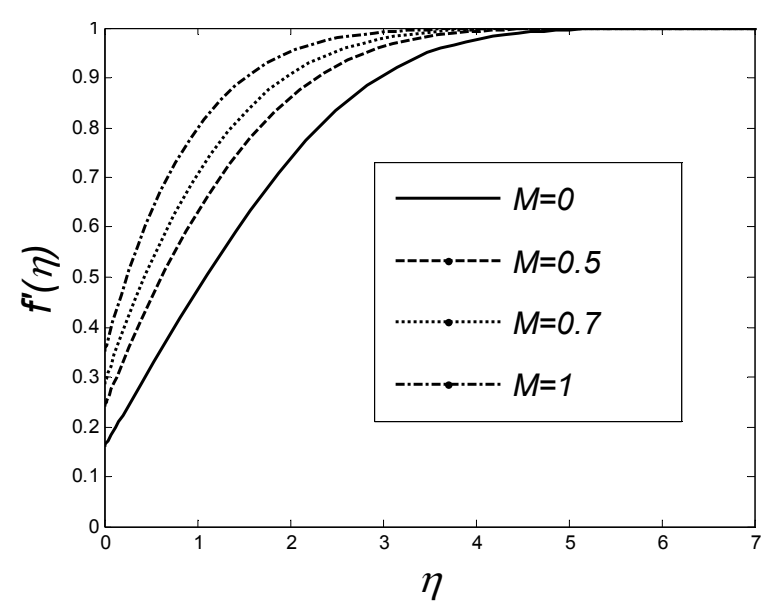

(a)

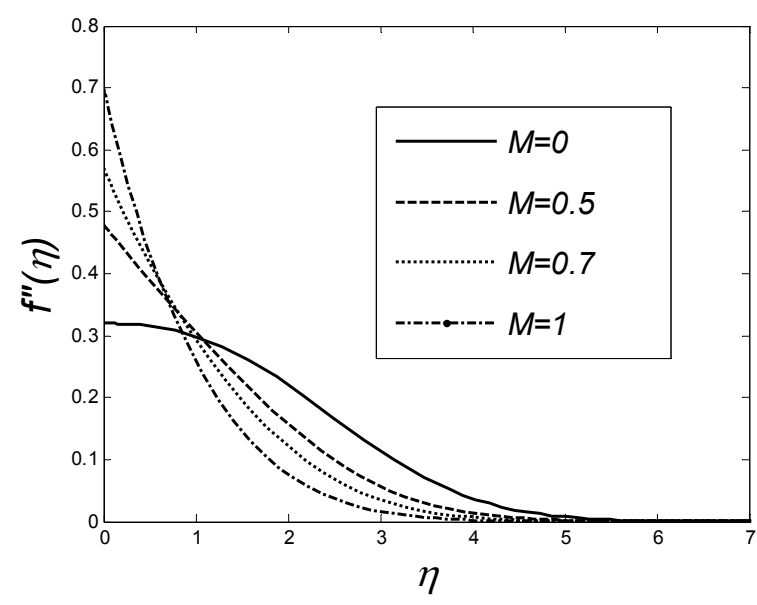

(b)

Actually, the right side of the Navier-Stokes equation is in effect a summation of body forces, see Equation (5). Thus, electromagnetic (Lorentz) force is a body force (force per unit volume) which is associated with additional forcing term in Navier-Stokes equation. As the sum of last two terms of the momentum equation $\left(u_{\infty}-u\right)$ is positive, see Equation (5), fluid motion in the both boundary layer region and adjacent to the wall increases as a result of Lorenz force. Consequently, the electrically conducting fluid receives a push from the magnetic force - the mechanism by which the magnetic field has the potential to manipulate an electrically conducting fluid in the micro scale system. The effect of the magnetic parameter on the velocity gradient profiles when $f_{w}=0.0, K=0.5$ has been illustrated in Figure $4 \mathrm{~b}$. By keeping in mind that $K \neq 0$, due to the slip condition at the wall, the velocity of fluid adjacent to the wall has some positive value and can be increased by either increasing the strengths of the slip coefficient or increasing additional momentum in the boundary layer. However, in the second one, the skin friction coefficient increases due to the import of the additional momentum in the boundary layer with the increase of magnetic parameter. Consequently, the momentum gain produced by Lorentz forces in boundary layer can result in an increase of the wall shear stress.

\subsection{Effects on Temperature Field and Heat Transfer}

Figure 5a illustrates the combined effect of the surface temperature parameter $k^{\prime}$, slip coefficient $K$ and the magnetic parameter $M$ on heat transfer rate $\left|\theta^{\prime}(0)\right|$. This suggests that the heat transfer rate of liquids increases significantly with the increase of slip flow coefficient, as the change from 0 to 5 yields an increase in the heat transfer rate over surface structure by up to around $100 \%$. Previous work along vertical surface has also illustrated similar consequence regarding to slip coefficient effects on heat transfer rate [14]. Cao and Baker have demonstrated that the heat transfer rate over vertical surface will be increased significantly with high slip coefficient, giving more than $100 \%$ as the flow varies from the no-slip condition to highly rarefied at slip coefficient equal to 5 [14]. It is also illustrated that the 
results demonstrate the heat transfer rate is increased by an increase of both parameters $k^{\prime}$ and $M$. As a result, it is interesting to conclude that the hydrodynamic slip as a potential boundary condition of convective heat transfer in the micro scale systems has capability of increasing the heat transfer rate along stationary surfaces either vertical or horizontal. Figure $5 \mathrm{~b}$ shows the variation of $\left|\theta^{\prime}(0)\right|$ as a function of $K$ for different $f_{w}$ values, respectively. The same consequence for the slip coefficient is illustrated as $K$ increases the heat transfer rate is increased. In addition, it is noted that an increase in mass suction tend to increase heat transfer rate whereas injection acts in the opposite way.

Figure 5. (a) Variation of $\left|\theta^{\prime}(0)\right|$ as function of $K$ for various values of $M$ and $k^{\prime}$ when $\mathrm{Ec}=0.1$ and $\operatorname{Pr}=5$. (b) Variation of $\left|\theta^{\prime}(0)\right|$ as function of $K$ for various values of $f_{w}$ when $\mathrm{Ec}=0.01, k^{\prime}=0.1, M=0.3$ and $\operatorname{Pr}=5$.

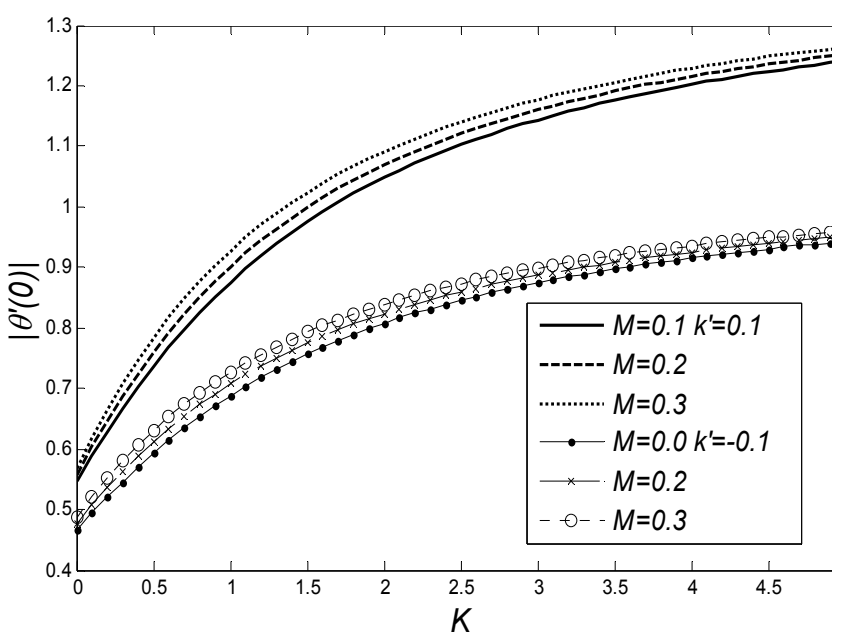

(a)

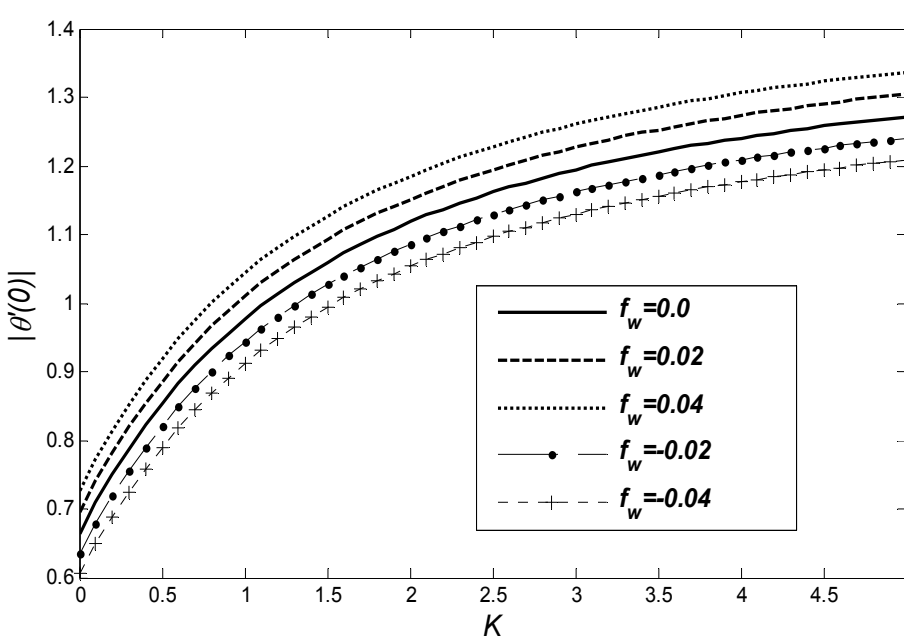

(b)

\subsection{Effects on Entropy Generation Analysis}

The following part presents the results for entropy generation analysis of MHD flow past open parallel microchannels embedded in a permeable surface. The effects of the involved parameters of the problem on both entropy generation number and Bejan number are presented and discussed in details based on Equation (24).

\subsubsection{Effect of Slip Coefficient}

In most thermal cooling systems, it is desirable to increase the heat transfer rate while the friction (or pressure drop) is decreased. It is very difficult to satisfy both conditions simultaneously, specially in macroscale systems since the friction irreversibility is usually reduced with a smaller surface area but a high heat transfer rate conversely requires a higher surface area. This aim can be satisfied in microscale systems based on slip flow regime where an increase in the slip velocity is capable of decreasing friction losses while increasing the heat transfer rate. It will be shown that the present study demonstrates that the proposed embedded surface microchannel system has additional benefits which can successfully reduce local entropy generation rates. Figure $6 a, b$ show the change of the entropy generation number as a 
function of slip coefficient and the number of embedded open parallel microchannels for different values of the dimensionless group parameter, $\operatorname{Br} \Omega^{-1}=5$ and $\mathrm{Br} \Omega^{-1}=10$, respectively.

Figure 6. $N_{s}$ as a function of $K$ for various values of $m^{\prime}$ at (a) $\mathrm{Br} \Omega^{-1}=5$ and (b) $\mathrm{Br} \Omega^{-1}=10$, when $f_{w}=0.01, \mathrm{X}=0.03, \mathrm{Re}=3500, \operatorname{Pr}=5, \mathrm{Ec}=0.01, M=0.3, k^{\prime}=-0.1, \zeta=0.000001$, $\lambda=0.0001$.

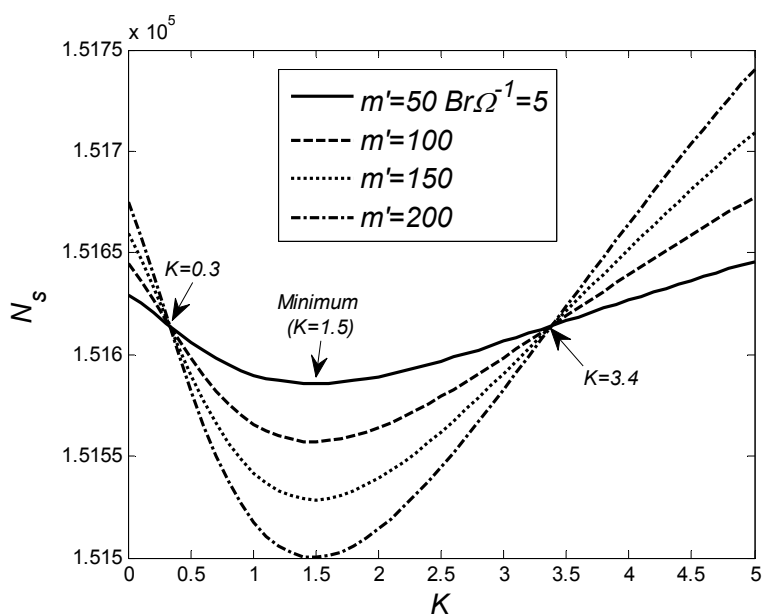

(a)

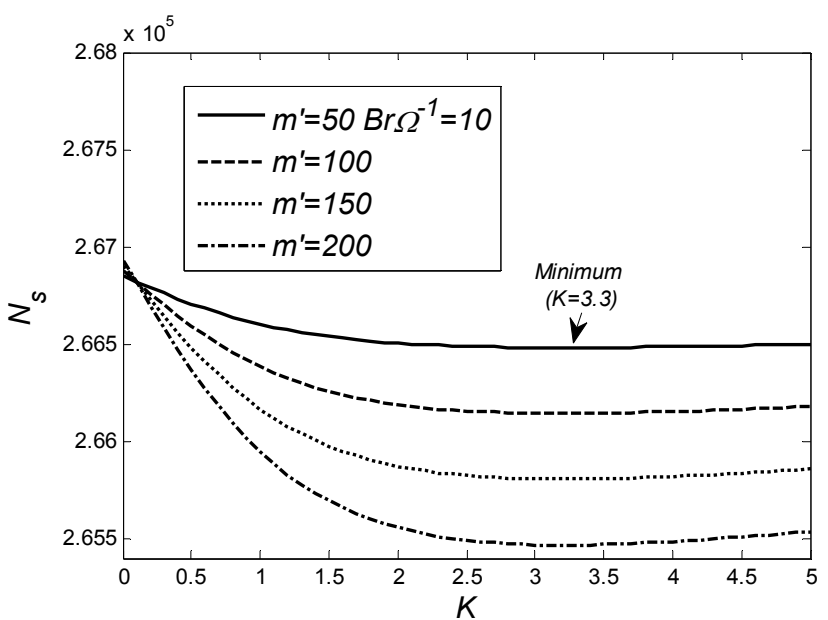

(b)

Here, it is demonstrated that the design of embedded open parallel microchannels yields an interesting result with respect to reduction of the entropy production of forced convection. We know that the slip inside the open microchannels should be considered, particularly in cases where a hydrophobic microchannel surface exists. First of all, it should be remembered that an increase in the slip coefficient tends to increase the heat transfer irreversibilities while it decreases friction losses along a stationary surface. On the other hand, the entropy generation number $N_{s}$ is comprised of friction, heat transfer and magnetic irreversibilities. Consequently, the slip coefficient is capable of decreasing $N_{s}$ when the irreversibility distribution ratio $\Phi$ is high. Thus, taking advantage of the slip flow regime reaching to a reduction in entropy production needs a high irreversibility distribution ratio $\Phi$. This consequence of slip effects is clearly appeared as a minimum point illustrated at $K=1.5$ which divides the entropy generation number into two parts (see Figure 6a). At the points to the left of the minimum; the slope of the tangent is negative, indicating that an increase in the $K$ tends to decrease the friction irreversibilities. As a result, the entropy generation number is also reduced where the decreasing effects of the friction irreversibilities is much more considerable compared with the increasing effects of temperature irreversibilities. It is observed that the entropy generation number changes the trend, after reaching the minimum corresponding to a specific slip coefficient. Similarly, at the points to the right, the slope is positive, i.e., higher $K$ values yield higher $N_{s}$ where increasing effects of the temperature irreversibilities is much more significant compared with decreasing effects of the friction irreversibilities. Then, the decreasing effect of the slip on the friction irreversibilities is not enough to reduce the total entropy generation. Therefore, it is essential to consider the projected values of the slip coefficients inside the microchannels in order to establish a proper design of the open parallel microchannels embedded within the surface due to a reduction in the exergy losses. 
However, this design can be efficiently improved based on an appropriate choice of the dimensionless group parameter $\mathrm{Br} \Omega^{-1}$. As noted before, an increase in the dimensionless group parameter $\mathrm{Br} \Omega^{-1}$ tends to simultaneously increase both friction and magnetic irreversibilities (see Equation (24)) which leads to both a high irreversibility distribution ratio $\Phi$ and low Bejan number. Thus, an increase in the dimensionless group parameter $\left(\mathrm{Br} \Omega^{-1}=10\right)$ can effectively improve our system (see Figure 6b). Here, the minimum point moves rightward and unpleasant effect of the high slip coefficients is going to be vanished. It should be noted that when the size of the region (as measured in $K$ ) is larger, it also has larger entropy generation numbers where the decreasing effect of the slip on the friction irreversibilities is not enough to reduce the total entropy generation.

\subsubsection{Effect of Number of Embedded Open Parallel Microchannels}

There are different regions of interest in Figure $6 \mathrm{a}$ which should be considered in details due to the assessment of the number of open microchannels. The region between $0<K<0.3$ is called as "ineffectual region" in which the influence of the slip coefficient on both friction and temperature irreversibilities is insignificant. It indicates that as a larger surface area results in an increased surface friction due to a larger number of embedded microchannels, when the slip coefficient inside the microchannels is not sufficient, so an increase in the number of microchannels tends to increase the entropy generation number, due to added surface friction. As a result, extra effort and cost associated with micromachining the surface to achieve a desired embedded microchannel surface cannot be justified. The region between $0.3<K<3.4$ is named as "effectual region" in which the influence of the slip coefficient on the system is considerable and an increase in the number of open parallel microchannels can effectively decrease the entropy generation number. Here, as the objective of this design, an increase in the number of open microchannels can successfully reduce entropy generation. The region $K>3.4$ is called "undesirable region" in which the influence of the slip coefficient on the temperature irreversibilities is much more considerable compared with the friction irreversibilities. Thus, the decreasing effect of the slip on friction losses is not capable of reducing the total entropy generation. Consequently, an increase in the number of open microchannels tends to increase the entropy generation number.

The design can be improved by the increase of the dimensionless group parameter, $\mathrm{Br} \Omega^{-1}$. It is observed that an increase in the dimensionless group parameter $\left(\mathrm{Br}^{-1}=8\right)$ can simultaneously display vanishing both undesirable regions: "ineffectual region" and "undesirable region", on the other hand, it is improving the "effectual region" which leads to reach a satisfying design of open microchannels embedded within surface where an increase in the number of open microchannels can decrease exergy losses in whole slip flow regime regions (see Figure 6b). It is noted that a reduction in $\operatorname{Br} \Omega^{-1}$ accompanies a rise in the Bejan number (see Figure 7a,b). At high slip coefficient, the Bejan number is high due to a small irreversibility distribution ratio $\Phi$ where the temperature irreversibilities are prominent. An increase in $\mathrm{Br} \Omega^{-1}$ can verify the desirable circumstances which are required for our system in order to an increase in the irreversibility distribution ratio $\Phi$ where it would be possible to efficiently take advantage of slip flow boundary conditions in our system. 
Figure 7. Bejan number as a function of $K$ for various values of $m^{\prime}$ at (a) $\mathrm{Br} \Omega^{-1}=5$ and (b) $\mathrm{Br} \Omega^{-1}=10$, when $f_{w}=0.01, \mathrm{X}=0.03, \mathrm{Re}=3500, \operatorname{Pr}=5, \mathrm{Ec}=0.01, M=0.3, k^{\prime}=-0.1$, $\zeta=0.000001, \lambda=0.0001$.

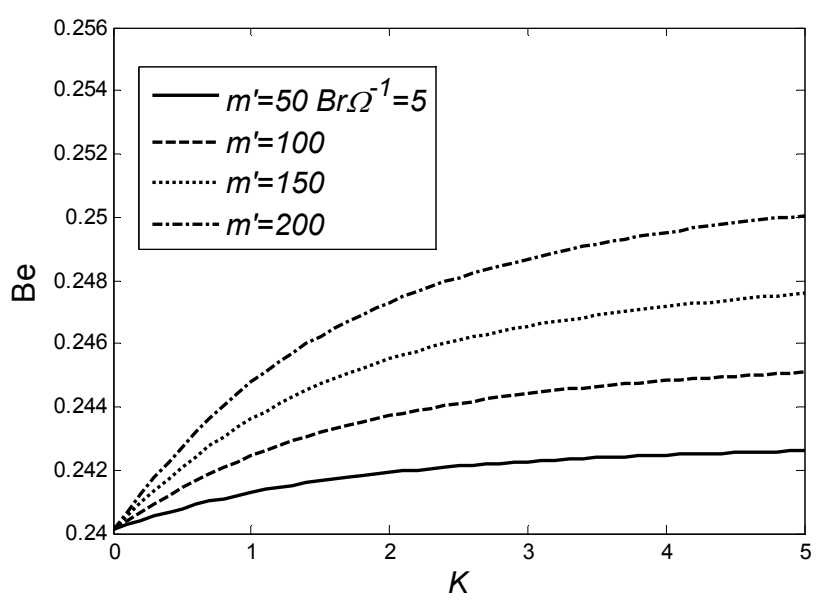

(a)

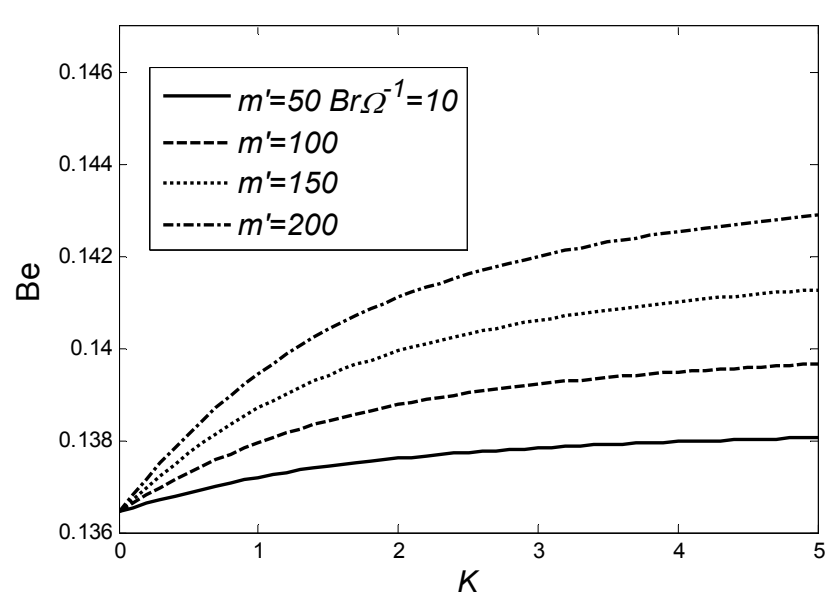

(b)

\subsubsection{Effect of Magnetic Field}

As explained, the entropy generation number $N_{s}$ is comprised of friction, heat transfer and magnetic irreversibilities. The effect of the magnetic parameter $M$ on the entropy generation number is shown in Figure $8 \mathrm{a}$. It is indicated that an increase in the $M$ tends to increase the entropy generation number since the magnetic parameter has an increasing effect on all friction, heat transfer and magnetic irreversibilities. The combined effect of the slip coefficient and magnetic parameter on the Bejan number is illustrated in Figure $8 \mathrm{~b}$. Here, it is observed that the Bejan number decreases with the increase of magnetic parameter $M$, due to its significant effect on friction irreversibilities. As a result, the irreversibility distribution ratio $\Phi$ is increased.

Figure 8. (a) Entropy generation number and (b) Bejan number as a function of $K$ for various values of magnetic parameter $M$ when $f_{w}=0.01, \mathrm{X}=0.03, \mathrm{Re}=3500, \operatorname{Pr}=5$, $\mathrm{Ec}=0.01, \mathrm{Br} \Omega^{-1}=10, k^{\prime}=0.1, m^{\prime}=100, \zeta=0.00001, \lambda=0.0001$.

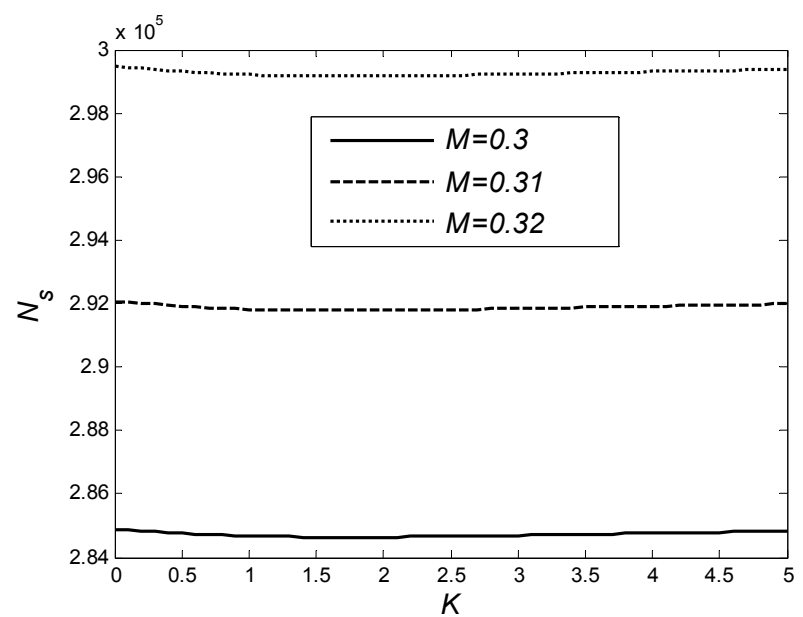

(a)

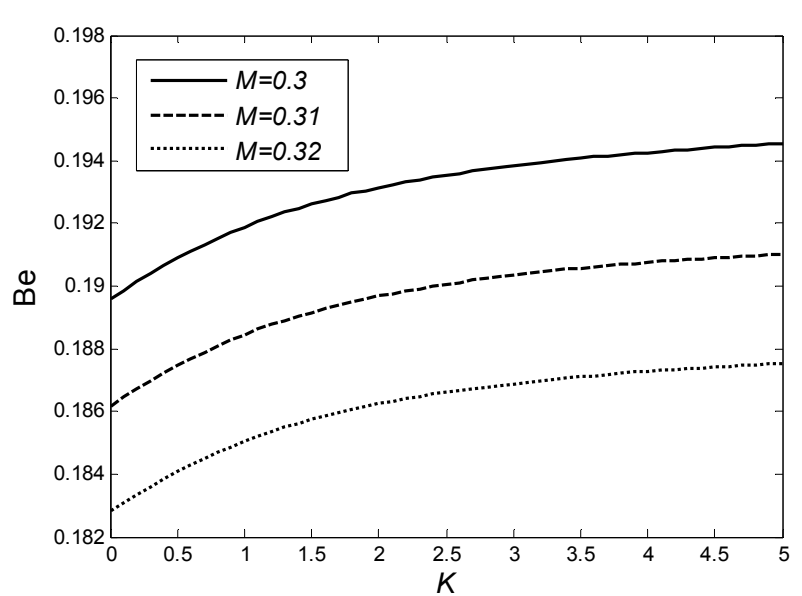

(b) 


\subsubsection{Effect of Suction/Injection}

Figure 9a,b illustrate the effect of the suction/injection parameter on the entropy generation number and Bejan number, respectively. The entropy generation number is lower for a higher slip coefficient, whereby the presence of the suction creates entropy along the surface, with a noticeable opposite effect resulting from injection. Moreover, Bejan number decreases when $f_{w}$ is increased for injection. It is also evident that Bejan number is increased in the case of suction, when compared to the injection.

Figure 9. (a) Entropy generation number and (b) Bejan number as a function of $K$ for various values of $f_{w}$ when $\operatorname{Br} \Omega^{-1}=10, \mathrm{X}=0.03, \operatorname{Re}=3500, \operatorname{Pr}=5, \mathrm{Ec}=0.01, M=0.3$, $k^{\prime}=0.1, m^{\prime}=100, \zeta=0.00001, \lambda=0.0001$.

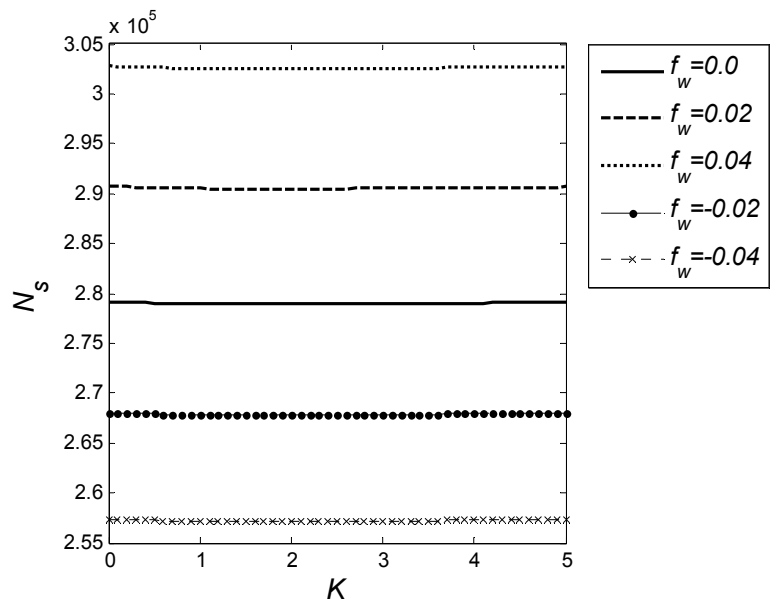

(a)

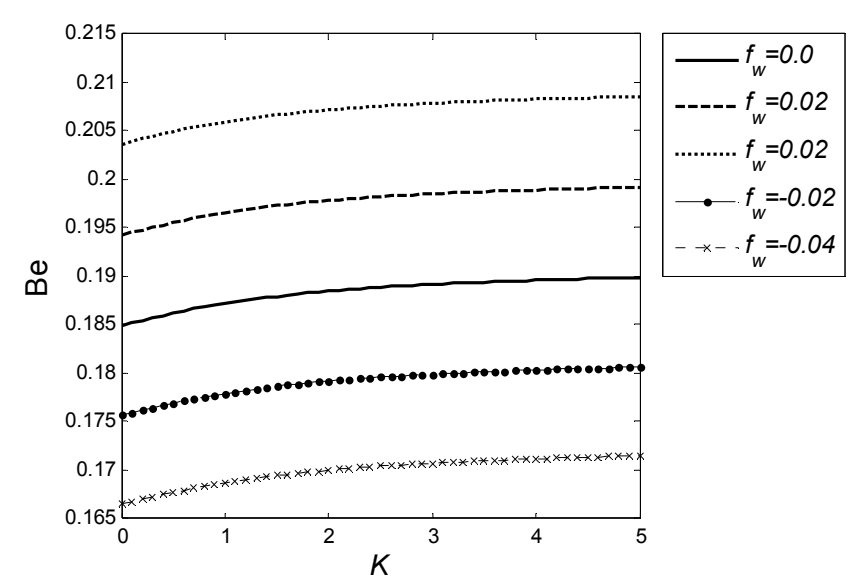

(b)

\subsubsection{Effect of Non-Dimensional Geometric Parameters}

Figure 10a,b illustrate the effect of $\lambda$ and $\zeta$ on entropy generation $N_{s}$ with changing, respectively. The $N_{s}$ shows an increase at higher microchannel depths, whereas it decreases at higher microchannel widths. This suggests that an increase in the width of the microchannels $\lambda$ tends to increase the slip flow effects along the width of the surface, causing $N_{s}$ to decrease. The influence of the non-dimensional geometric parameters on the Bejan number is presented in Figure 11a,b which it is increased with the increase in $\lambda$. It indicates that an increase in the width of the microchannels decreases the irreversibility distribution ratio with the increase of heat transfer irreversibilities. Further, it is noted that a decrease in the microchannel depth $\zeta$ accompanies a slight rise in the Bejan number. 
Figure 10. Effect of (a) $\lambda$ and (b) $\zeta$ on Entropy generation number when $\mathrm{Br}^{-1}=10$, $f_{w}=0.01, \mathrm{X}=0.03, \operatorname{Re}=3500, \operatorname{Pr}=5, \mathrm{Ec}=0.01, M=0.3, k^{\prime}=0.1$, and $m^{\prime}=100$.

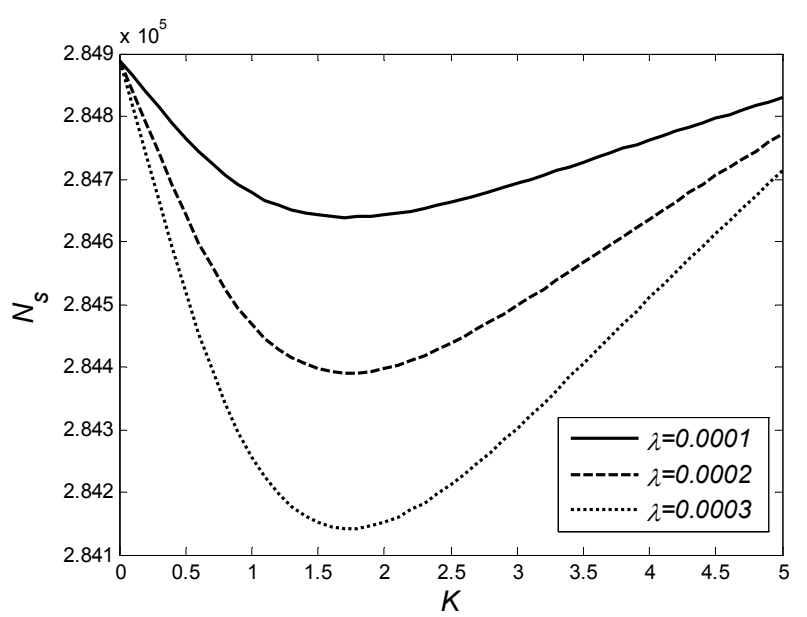

(a)

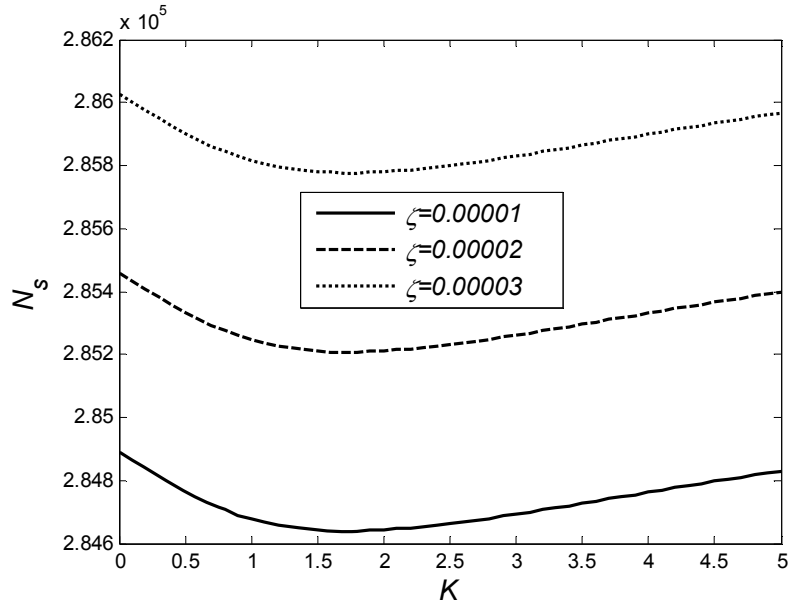

(b)

Figure 11. Effect of (a) $\lambda$ and (b) $\zeta$ on Bejan number when $\mathrm{Br}^{-1}=10, f_{w}=0.01, \mathrm{X}=0.03$, $\operatorname{Re}=3500, \operatorname{Pr}=5, \mathrm{Ec}=0.01, M=0.3, k^{\prime}=0.1$, and $m^{\prime}=100$.

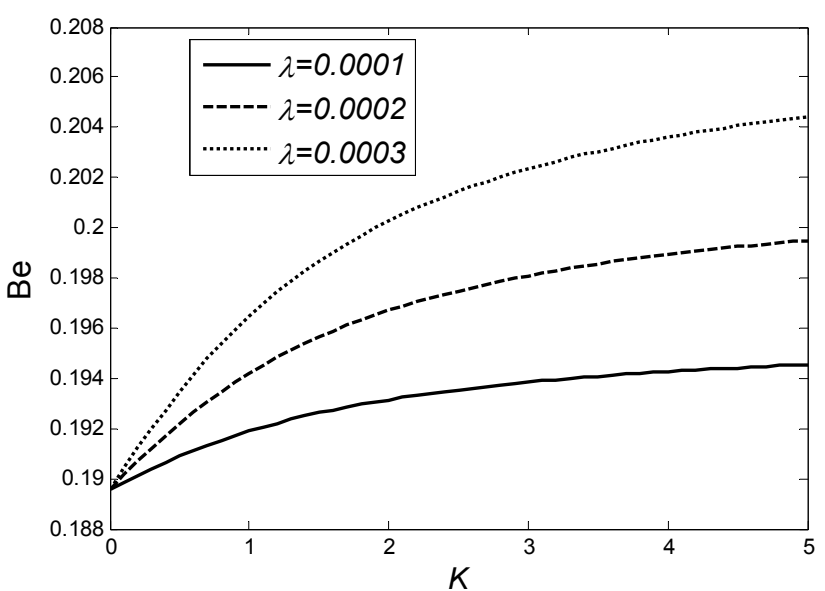

(a)

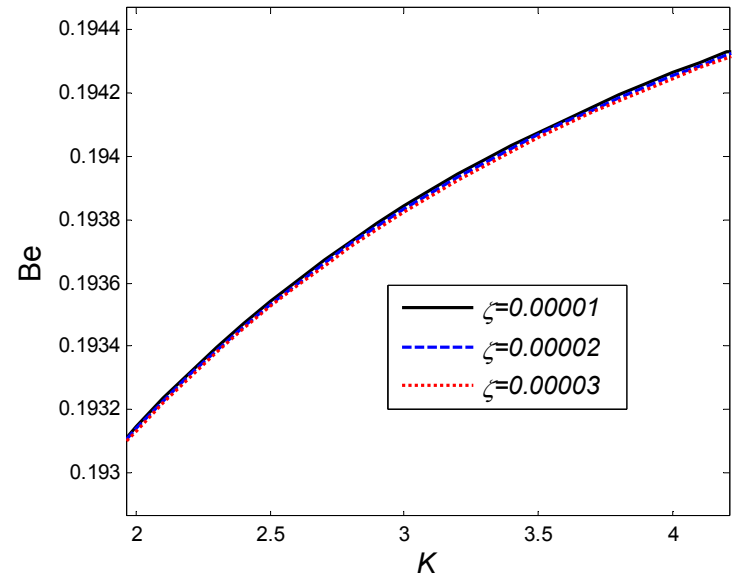

(b)

\section{Conclusions}

The entropy generation in electrically conducting fluid flow past open parallel microchannels embedded in a micropatterned permeable surface subjected to a transverse magnetic field at a prescribed surface temperature (PST) is analysed. In the present work, the free stream velocity $u_{\infty}$, outside the boundary layer is also affected by magnetic field, thus, the Lorenz force can push the fluid forward to accelerate the fluid motion. Based on EBSM, the entropy generation number is formulated by an integral of local entropy generation rate on the width of the surface. It is noted that the entropy generation number $N_{s}$ decreases with the increase of injection and $\lambda$, while it increases with the increase of suction, $\mathrm{Br} \Omega^{-1}, k^{\prime}, M$ and $\zeta$. However, the geometrical parameters $\left(m^{\prime}, \zeta, \lambda\right)$ have a smaller effect on $N_{s}$ than flow parameters $\left(M, \mathrm{Br} \Omega^{-1}\right)$. The results demonstrate that in the present surface microprofiling design, the value of slip coefficient, $K$ is suggested to be selected more than 0.3 reaching an effective reduction in exergy losses. As the final objective of the study, an increase in the 
number of open microchannels can successfully reduce entropy generation. The present surface-embedded microchannels design can also be much more effective by the increase of the dimensionless group parameter, where an increase in $\mathrm{Br} \Omega^{-1}$ can simultaneously display vanishing both "ineffectual region" and "undesirable region", on the other hand, it tends to improve the "effectual region" which leads to reach a satisfying design of decreasing entropy generation in slip flow regime. The presented design is able to be applied on a variety of micro scale systems such as micromixing technologies, etc.

\section{Conflicts of Interest}

The authors declare no conflict of interest.

\section{References}

1. Nisar, A.; Afzulpurkar, N.; Mahaisavariya, B.; Tuantranont, A. MEMS-based micropumps in drug delivery and biomedical applications. Sens. Actuators B Chem. 2008, 130, 917-942.

2. Ibáñez, G.; Cuevas, S. Entropy generation minimization of a MHD (magnetohydrodynamic) flow in a microchannel. Energy 2010, 35, 4149-4155.

3. Kleinstreuer, C.; Li, J.; Koo, J. Microfluidics of nano-drug delivery. Int. J. Heat Mass Trans. 2008, 51, 5590-5597.

4. Avsec, J. Nanofluid and Ferrofluid Slip Flow in Rectangular and Circular Microchannels. In Proceedings of 7th Euromech Solid Mechanics Conference, Lisbon, Portugal, 7-11 September 2009.

5. Capretto, L.; Cheng, W.; Hill, M.; Zhang, X. Micromixing within microfluidic devices. Top. Curr. Chem. 2011, 304, 27-68.

6. Wu, W.-I.; Selvaganapathy, P.R.; Ching, C.Y. Transport of particles and microorganisms in microfluidic channels using rectified ac electro-osmotic flow. Biomicrofluidics 2011, 5, 013407.

7. Yazdi, M.H.; Abdullah, S.; Hashim, I.; Sopian, K. Entropy generation analysis of open parallel microchannels embedded within a permeable continuous moving surface: Application to magnetohydrodynamics (MHD). Entropy 2012, 14, 1-23.

8. Naterer, G.F.; Chomokovski, S. Entropy-based surface microprofiling for passive near-wall flow control. J. Micromech. Microeng. 2007, 17, doi:10.1088/0960-1317/17/10/028.

9. Martin, M.J.; Boyd, I.D. Blasius Boundary Layer Solution with Slip Flow Conditions. In Proceedings of Rarefied Gas Dynamics: 22nd International Symposium, Sydney, Australia, 9-14 July 2000; AIP publishing: New York, NY, USA, 2001; Volume 585, pp. 518-523.

10. Martin, M.J.; Boyd, I.D. Momentum and heat transfer in a laminar boundary layer with slip flow. J. Thermophys. Heat Trans. 2006, 20, 710-719.

11. Vedantam, N.K.; Parthasarathy, R.N. Effects of Slip on the Flow Characteristics of Laminar Flat Plate Boundary-Layer. In Proceedings of ASME 2nd Joint U.S.-European Fluids Engineering Summer Meeting Collocated With the 14th International Conference on Nuclear Engineering (FEDSM2006), Miami, FL, USA, 17-20 July 2006. 
12. Yazdi, M.H.; Abdullah, S.; Hashim, I.; Zaharim, A.; Sopian, K. Friction and Heat Transfer in Slip Flow Boundary Layer at Constant Heat Flux Boundary Conditions. In Proceedings of the 10th WSEAS International Conference on Mathematical Methods, Computational Techniques and Intelligent Systems, Corfu, Greece, 26-28 October 2008.

13. Yazdi, M.H.; Abdullah, S.; Hashim, I.; Nopiah, Z.M.; Zaharim, A.; Sopian, K. Convective Heat Transfer of Slip Liquid Flow Past Horizontal Surface within the Porous Media at Constant Heat Flux Boundary Conditions. In Proceedings of the American Conference on Applied Mathematics: Recent Advances in Applied Mathematics, Cambridge, MA, USA, 27-29 January 2010.

14. Cao, K.; Baker, J. Slip effects on mixed convective flow and heat transfer from a vertical plate. Int. J. Heat Mass Trans. 2009, 52, 3829-3841.

15. Aziz, A. Hydrodynamic and thermal slip flow boundary layers over a flat plate with constant heat flux boundary condition. Commun. Nonlinear Sci. Numer. Simul. 2010, 15, 573-580.

16. Yazdi, M.H.; Abdullah, S.; Hashim, I.; Sopian, K. Slip MHD liquid flow and heat transfer over non-linear permeable stretching surface with chemical reaction. Int. J. Heat Mass Trans. 2011, 54, 3214-3225.

17. Yazdi, M.H.; Abdullah, S.; Hashim, I.; Sopian, K. Slip MHD Flow over Permeable Stretching Surface with Chemical Reaction. In Proceedings of the 17th Australasian Fluid Mechanics Conference, Auckland, New Zealand, 5-9 December 2010.

18. Hayat, T.; Qasim, M.; Mesloub, S. MHD flow and heat transfer over permeable stretching sheet with slip conditions. Int. J. Numer. Meth. Fl. 2011, 66, 963-975.

19. Qasim, M.; Hayat, T.; Hendi, A.A. Effects of slip conditions on stretching flow with ohmic dissipation and thermal radiation. Heat Trans.-Asian Res. 2011, 40, 641-654.

20. Turkyilmazoglu, M. Analytic heat and mass transfer of the mixed hydrodynamic/thermal slip MHD viscous flow over a stretching sheet. Int. J. Mech. Sci. 2011, 53, 886-896.

21. Bhattacharyya, K.; Mukhopadhyay, S.; Layek, G. MHD boundary layer slip flow and heat transfer over a flat plate. Chin. Phys. Lett. 2011, 28, 024701.

22. Rahman, M.M. Locally similar solutions for hydromagnetic and thermal slip flow boundary layers over a flat plate with variable fluid properties and convective surface boundary condition. Meccanica 2011, 46, 1127-1143.

23. Yazdi, M.H.; Abdullah, S.; Hashim, I.; Sopian, K. Effects of viscous dissipation on the slip MHD flow and heat transfer past a permeable surface with convective boundary conditions. Energies 2011, 4, 2273-2294.

24. Naterer, G.F. Surface micro-profiling for reduced energy dissipation and exergy loss in convective heat transfer. Microscale Thermophys. Eng. 2005a, 9, 213-236.

25. Naterer, G.F. Adaptive surface microprofiling for microfluidic energy conversion. J. Thermophys. Heat Trans. 2004, 18, 494-501.

26. Naterer, G.F. Reducing energy availability losses with open parallel microchannels embedded in a micropatterned surface. Int. J. Energy Res. 2005b, 29, 1215-1229.

27. Naterer, G.F.; Glockner, P.S.; Thiele, D.; Chomokovski, S.; Venn, G.; Richardson, G. Surface micro-grooves for near-wall exergy and flow control: Application to aircraft intake de-icing. J. Micromech. Microeng. 2005, 15, doi:10.1088/0960-1317/15/3/010. 
28. Yazdi, M.H.; Abdullah, S.; Hashim, I.; Sopian, K.; Zaharim, A. Entropy generation analysis of liquid fluid past embedded open parallel microchannels within the surface. Eur. J. Sci. Res. 2009b, 28, 462-470.

29. Yazdi, M.H.; Abdullah, S.; Hashim, I.; Sopian, K. Second Law Analysis of MHD Flow Over Open Parallel Microchannels Embedded in a Micropatterned Surface. In Proceedings of 10th WSEAS International Conference on Heat Transfer, Thermal Engineering and Environment, Istanbul, Turkey, 21-23 August 2012.

30. Tretheway, D.C.; Meinharta, C.D. Apparent fluid slip at hydrophobic microchannel walls. Phys. Fluids 2002, 14, L9.

31. Niavarani, A.; Priezjev, N.V. The effective slip length and vortex formation in laminar flow over a rough surface. Phys. Fluids 2009, 21, 052105.

32. Shamshiri, M.; Ashrafizaadeh, M.; Shirani, E. Effects of rarefaction, viscous dissipation and rotation mode on the first and second law analyses of rarefied gaseous slip flows confined between a rotating shaft and its concentric housing. Energy 2011, 37, 359-370.

33. Tretheway, D.C.; Meinhart, C.D. A generating mechanism for apparent fluid slip in hydrophobic microchannels. Phys. Fluids 2004, 16, 1509-1515.

34. $\mathrm{Xu}, \mathrm{H}$. Erratum to "An explicit analytic solution for convective heat transfer in an electrically conducting fluid at a stretching surface with uniform free stream". Int. J. Eng. Sci. 2007, 2, 716-717.

35. Woods, L.C. The Thermodynamics of Fluid Systems; Oxford University Press: New York, NY, USA, 1986; Volume 2.

36. Ibrahim, F.; Hassanien, I. Local nonsimilarity solutions for mixed convection boundary layer flow of a micropolar fluid on horizontal flat plates with variable surface temperature. Appl. Math. Comp. 2001, 122, 133-153.

(C) 2013 by the authors; licensee MDPI, Basel, Switzerland. This article is an open access article distributed under the terms and conditions of the Creative Commons Attribution license (http://creativecommons.org/licenses/by/3.0/). 